\title{
Eligio Ancona: Memorias de un alférez y sus ediciones
}

\author{
MANUEl Sol \\ Universidad Veracruzana \\ solm@prodigy.net.mx
}

\begin{abstract}
Resumen: Después de algunos datos sobre la biografía y la novela de Eligio Ancona, se describen las tres ediciones de las Memorias de un alférez; se examinan algunas de sus variantes mediante las cuales se demuestra que la más contaminada es la que preparó Antonio Castro Leal en 1964 para su edición de La novela del México colonial, entre otras razones, por haber tomado como texto base la edición de la Editorial Yucatanense "Club del Libro", publicada en 1950; por no haber consultado la prínceps, publicada por José María Pino Suárez en 1904; y por haber corregido el texto según prejuicios gramaticales.
\end{abstract}

Se propone una edición que establezca su texto crítico a partir de la prínceps, la más próxima a la última voluntad artística de su autor; y que venga acompañada con una serie de notas léxicas y, en general, culturales, que la sitúen en su circunstancia histórica y literaria.

Aвstract: After some data about the biography and novel of Eligio Ancona, three editions of Memorias de un alférez are described; some of the variations are examined through which it is shown that the most imperfect was that prepared by Antonio Castro Leal in 1964 for his edition of La novela del México colonial, among other reasons, for having used as a base text the edition of Editorial Yucatanense "Club del Libro" (Book Club), published in 1950; for not having consulted the editio princeps, published by José María Pino Suárez in 1904; and for having corrected the text according to certain grammatical prejudices.

An edition is proposed which establishes its critical text based on the editio princeps, the closest to the final artistic choice of the author; and which would be presented accompanying a series of lexical and generally cultural notes, which may situate the work in its historical and literary circumstance.

Palabras Clave: Eligio Ancona, novela histórica, novela colonial, crítica textual, ecdótica.

KeYwords: Eligio Ancona, historical novel, colonial novel, textual criticism, ecdotics.

Eligio María Ancona Castillo nació en la ciudad de Mérida, el $1^{\circ}$ de diciembre de 1836. Después de cursar los estudios elementales en la escuela de su padre, inició los cursos preparatorios en el Seminario Conciliar de San Ildefonso. Más tarde se inscribió en la Universidad 
del Estado para iniciar la carrera de Jurisprudencia, en la que obtuvo el título de abogado en 1862, entonces ya con el nombre de Colegio Civil. Inició sus labores literarias a principios de 1860 en La Guirnalda, y más tarde en La Burla, El Constitucional y El Álbum Yucateco. Pero indudablemente, durante estos años el acontecimiento literario más importante fue la publicación de su primera novela larga titulada $\mathrm{La}$ mestiza (Mérida: Imprenta de la Sociedad Tipográfica, 1861).

Al conocerse, a finales de 1861, la presencia de la escuadra de España, y la inminente de Inglaterra y Francia, el $1^{\circ}$ de enero de 1862 publicó el editorial de La sombra de Morelos, en el que exhortaba a todos los mexicanos para que olvidaran sus diferencias ideológicas y unieran sus fuerzas en la lucha contra los invasores.

Durante la intervención francesa, a pesar de las diversas tentativas que llevaron a cabo las autoridades imperiales en la península para que desistiera de sus ideas, como la reedición de su segunda y tercera novela, La Cruz y la Espada y El filibustero en las prensas de Rosa y Bouret, en París - que se habían publicado en Mérida, en 1864, por Leonardo Cervera-, fundó La Píldora y Yucatán para combatir el imperio y formó parte del grupo liberal acaudillado por Manuel Cepeda Peraza, el principal opositor en Yucatán a la política de Maximiliano de Habsburgo.

Al triunfo de la República en la península, el periódico La Juventud, en septiembre de 1867, propuso a Eligio Ancona como diputado federal y un mes más tarde como Vicegobernador, después de que había ocupado la Secretaría de Gobierno al lado del general Cepeda Peraza. $\mathrm{Al}$ efectuarse las elecciones, triunfó como Vicegobernador; pero prefirió trasladarse a México a ejercer sus funciones como diputado.

El 3 de abril el presidente Benito Juárez lo nombró gobernador interino del estado de Yucatán (La Razón del Pueblo, Mérida, 6 de abril de 1868: 1); y años más tarde, en marzo de 1875 tomó posesión del estado de Yucatán como gobernador constitucional para un período que terminaría el 31 de enero de 1878 (Menéndez: 101, 103-104), pero renunció unas semanas después del triunfo de las huestes porfiristas, en la batalla de Tecoac, el 16 de noviembre de 1876, que habían proclamado el Plan de Tuxtepec. Siendo gobernador contrajo matrimonio civil con Manuela Albertos Zavalegui.

Aun durante el desempeño de sus actividades políticas, nunca abandonó el cultivo de las letras, pues en 1869, encontrándose en la Cámara de Diputados, buscó en la ciudad de México editor para su novela Los 
mártires del Anábuac, que no se publicó sino un año después, en 1870, en la imprenta de José Batiza (Algaba 2012: 101-102). Una novela indianista, "la más indianista del grupo romántico mexicano" y por lo tanto "la más antiespañola", según opinión de Concha Meléndez (9596). Y no hay que pasar por alto que la novela se terminaba de redactar en 1869, esto es, cuando se celebraban los 350 años del inicio de la conquista de México, y seguramente a Ancona le habría gustado que se hubiera publicado durante ese año para acallar en parte los gritos de entusiasmo y de celebración de todos los gachupines.

Pero ahora, libre de compromisos políticos, pudo con más tiempo dedicarse a las labores literarias. Fueron estos años de una gran actividad historiográfica y humanística, pues entre 1878 y 1880 aparecieron los cuatro tomos de su Historia de Yucatán desde la época más remota hasta nuestros días (Mérida: Imprenta de Manuel Heredia Argüelles). En 1879, también en las prensas de Manuel Heredia Argüelles, apareció la edición definitiva de El conde de Peñalva, otra de sus grandes novelas, cuyas primeras entregas habían visto la luz en su propia imprenta en 1866 cuando editaba La Píldora.

Durante los últimos años de su vida desempeñó varios puestos públicos; como Juez de Distrito (1885), Magistrado de Circuito de Mérida (1886) y Presidente del Consejo de Instrucción Pública (1888-1889). En 1891 fue nombrado Magistrado de la Suprema Corte de Justicia de la Nación y finalmente, a principios de 1893, embajador en Francia por indicaciones del presidente Porfirio Díaz (Ignacio Manuel Altamirano, Cónsul General de México en París, había muerto en San Remo el 13 de febrero de 1893). Y cuando hacía la familia los preparativos para viajar a Europa enfermó de escarlatina y murió el 3 de abril de 1893. Tres días después fue sepultado en la Rotonda de los Hombres Ilustres.

Las Memorias de un alférez, la última novela que escribió Eligio Ancona, fue publicada de manera póstuma, en 1904, por José María Pino Suárez (1869-1913), en la imprenta de El Peninsular. Pino Suárez, nacido en Tenosique, Tabasco, inició sus primeros estudios en su pueblo, los terminó en el puerto de Progreso y se inscribió inmediatamente en el Seminario de San Ildefonso, en Mérida; al terminar su bachillerato, ingresó en la escuela de Jurisprudencia, también en Mérida, en la que obtuvo el título de abogado, en 1894. La figura de Eligio Ancona debió serle conocida desde su más temprana juventud; independientemente de vivir en la misma ciudad y haber hecho los mismos estudios, Ancona 
era un ejemplo a seguir por sus ideas liberales, su trayectoria política y su labor de escritor.

Las Memorias de un alférez se publicó en dos tomos, que correspondían a su primera y segunda parte. Una edición modesta, a la rústica, en octavo, cuyo primer tomo iba adornado con una fotografía del autor y precedido de una "Introducción" de su editor que también se reprodujo en las páginas de El Peninsular, el $1^{\circ}$ de diciembre de 1904.

La recepción de las Memorias de un alférez, a pesar de ser la mejor obra narrativa de Eligio Ancona, en el momento de publicarse fue nula, salvo la "Introducción" de José María Pino Suárez y unas notas aparecidas en las páginas de El Peninsular, firmadas por Latino (1904: 1; 1905: 1). Permaneció en el olvido por casi medio siglo, hasta que, en 1949, la Editorial Yucatanense, "Club del Libro", volvió a publicarla, en Mérida, también en dos tomos, con la "Introducción" de José María Pino Suárez. Esta edición corrige las erratas evidentes de la prínceps, pero, como suele ocurrir en todo acto de copia, se reimprimió con otras erratas y algunas variantes, estas últimas con la intención de modernizar el texto. Además se le puso título a los capítulos, según se explica en una leyenda que se encuentra al término del índice del primer y segundo tomo: "(Los títulos de los diversos capítulos fueron agregados por la editorial Club del Libro)". Esta tendencia de ponerle títulos a las novelas del siglo XIX en las ediciones modernas o contemporáneas, sobre todo, cuando se trata de novelas de folletín o por entregas, me parece una torpeza de lesa estética, pues se apunta el contenido del capítulo, y se anula o contrarresta la técnica de esta clase de narraciones, uno de cuyos méritos radica principalmente en mantener pendiente o en suspenso la atención del lector mediante diversas incógnitas que el narrador va aclarando al final de cada una de las unidades narrativas o al final de la narración.

En 1964, Antonio Castro Leal en el primer volumen de su edición de La novela del México colonial (México: Aguilar, 1964), incluyó de Eligio Ancona, y en este orden, Los mártires del Anábuac, El filibustero y las Memorias de un alférez. Para Los mártires del Anábuac tomó como texto base la edición de la Editorial Yucatanense "Club del Libro", publicada en dos tomos, en 1951, hecha en Mérida; para la de El filibustero, la de la Editorial Yucatanense "Club del Libro", publicada en dos tomos, en 1950; y para las Memorias de un alférez, también la de la Editorial Yucatanense "Club del Libro", editada en 1949. Y como suele 
ocurrir, la edición más alejada en el tiempo cuando se copia la inmediata anterior y no se edita mediante los métodos de la crítica textual, resulta la más contaminada y la más infiel a la prínceps. Lo cual no es nada extraño en las ediciones preparadas por Antonio Castro Leal, entre otras razones, por su descuido y sobre todo por su afán de corregir y "mejorar" el original o la edición que tomó como texto base, según prejuicios culturales y gramaticales (léxicos y sintácticos).

Veamos algunos ejemplos tomados de las Memorias de un alférez. Cito en primer lugar la lección establecida tomando como texto base la de 1904, publicada por El Peninsular (P); después la de la Editorial Yucatanense (EY); y finalmente la de Antonio Castro Leal $(C L){ }^{1}$

1. balbutí: balbucí $C L$ (Primera Parte, III).

2. amada: amante $C L$ (Primera Parte, IV).

3. Acanceh : Acaneh $C L$ (Primera Parte, IV).

4. se convertían: se convergían EY, CL (Primera Parte, IV).

5. desapiadada: despiadada EY, CL (Primera Parte, VII).

6. criada : dueña $E Y, C L$ (Primera Parte, VII).

7. perjuicio : perjurio $E Y, C L$ (Primera Parte, IX).

8. fotografiada : grabada $C L$ (Primera Parte, XI).

9. mueblaje: moblaje $C L$ (Primera Parte, XIV).

10. desalentado: desatentado EY, CL (Segunda Parte, III).

11. participio : parte $C L$ (Segunda Parte, IV). Otras muchas veces no corrige $C L$ y siempre deja participio.

12. vergüenza : venganza $C L$ (Segunda Parte, IV).

13. confusión: confesión $E Y$, CL (Segunda Parte, VIII).

1. Durante el siglo XIX, aunque la Academia Española de la Lengua había aceptado el verbo balbucear en su diccionario desde 1852, innumerables escritores mexicanos, entre los que podría citarse a Ignacio Manuel Altamirano y Vicente Riva Palacio, seguían utilizando el verbo balbutir, derivado del balbutio, balbutis, balbutire, o bien tenían presente que en latín existía el participio presente balbutiens, balbutientis, y que en su forma española se puede documentar en don Enrique de Villena y en San Juan de la Cruz. Así pues, no es raro encontrar

${ }^{1}$ Utilizo la segunda reimpresión de la cuarta edición, la última revisada por Antonio Castro Leal: La novela del México colonial, t. I, México: Aguilar, 1982, pp. 805-1002. 
conjugado el presente como balbute o el pretérito como balbutió o el gerundio como balbutiendo. Y no era para menos, como dice Rufino José Cuervo en sus Apuntaciones críticas sobre el lenguaje bogotano, pues la conjugación era medio escabrosa, pues en cuanto al presente no se sabía si decir balbuzo o balbuzco. "Pero sea ello lo que se quiera - concluye el filólogo colombiano- balbucir no puede usarse sino cuando la terminación es $i$ o comienza por $i$, balbucí, balbuciendo, o bien $e$, balbuce"; y en las demás formas debe utilizarse "balbucear; usado hoy a cada paso por buenos escritores" (Cuervo: 183). Eligio Ancona, que había estudiado latín en el Seminario de San Ildefonso, en Mérida, finalmente prefirió utilizar la forma balbutir y así en las Memorias de un alférez escribió balbutí, balbutió, balbutiendo, balbutian; sin embargo en La Mestiza, La Cruz y la Espada, El filibustero y Los mártires del Anábuac, también se encuentran las variantes balbució, balbuceó, balbuciente, balbuceante, etc. Y en El conde de Peñalva, publicada en 1879 , de la que se publicaron algunas entregas en 1866, alternan las variantes balbuceó y balbutió. Podría pensarse que la elección de balbutir se deba a los editores de la primera edición de las Memorias de un alférez y no a Ancona. Imposible saberlo. Y mientras no se encuentre el manuscrito, lo cual parece imposible, habría que respetar la edición de El Peninsular.

2. Cuando en el capítulo IV de la Primera Parte, la señora Manresa le cuenta al alférez don Ramiro de Salazar la historia de Camila, y en particular la primera visita que le hace don Lucas de Gálvez, le refiere que en aquella ocasión se encontraba en su casa un antiguo pretendiente, que al notar la presencia del Gobernador y Capitán General, se escondió en un cuarto aledaño, del que no se ausentó sino hasta el otro día, a pesar del reto y de las ofensas de que había sido objeto:

Cuando al día siguiente salió de la alcoba el Capitán General antes de rayar el alba, la puerta del tocador estaba abierta de par en par, y en el interior sólo encontró espejos, polvos y pomadas. El hombre de la noche anterior había desaparecido, y su afortunado rival no pudo nunca averiguar su nombre. Con Camila no volvió a hablar jamás de este incidente, y en cuanto al embozado que le acompañó hasta la puerta de la casa de su amada [las cursivas son mías en las palabras afectadas de aquí en adelante], protestó no haber visto salir a nadie hasta la hora en que se retiró. 
El narrador escribe amada, que es la palabra exacta, pues aunque don Lucas de Gálvez tenía noticias de la belleza de Camila y la había conocido días antes en la quinta El Rosario (después llamada Walix), en los alrededores de Mérida, nunca la había visitado en su casa. Y aunque con el tiempo se convertirá en su amante, en la acepción de alguien que mantiene con otra persona relaciones sexuales irregulares, en esa primera ocasión la palabra más adecuada para referirse a ella era la palabra amada. "Amante", como cambia la palabra Castro Leal, se deriva del participio activo o presente del verbo amare, y aunque en español tiene un valor más bien nominal, a diferencia del latín el que alternaba con el verbal incluso con objeto directo, se utiliza en algunas ocasiones para indicar una acción presente: escribiente es el que escribe, hablante, el que habla, oyente el que oye, etc., y amante, en su acepción gramatical más inmediata, es el que ama como cuando se dice "una esposa amante" o "él es un amante de la música". Cuando don Lucas de Gálvez se da cuenta de la presencia de alguien más en la casa de Camila, monta en cólera y la increpa:

“-¿Qué significa esto señora? — preguntó con voz alterada.

“-Señor —balbutió la joven—, yo... no sé si...

"-No quiero daros tiempo para inventar una mentira, digna de una dama de Calderón, y yo mismo voy a deciros lo que significa esa puerta que acaba de cerrarse y el temblor que agita vuestra lengua. Todo esto quiere decir simplemente que a pesar del amor que creía haberos inspirado, creyendo neciamente en vuestras protestas, no habéis tenido por conveniente retirar a vuestro antiguo amante. Insensato de mí que por la primera vez llegué a confiar en el amor de una mujer".

Como resulta claro, don Lucas de Gálvez sí emplea correcta y exactamente la palabra amante e incluso en la acepción moderna que Castro Leal quiso darle con su corrección al texto del narrador.

3. Acanceh es un pueblo cuyo nombre significa 'bramido de venado', que debió ser importante en la época prehispánica, según las ruinas que todavía pueden apreciarse. Se encuentra localizado en el centro norte del estado de Yucatán y actualmente dista de Mérida 33 kilómetros en dirección sureste. "Acaneh", como escribe Castro Leal, es una errata.

4. En el capítulo IV de la Primera Parte, cuando el alférez Ramiro de Salazar se encuentra por primera vez a María, en la iglesia del Convento 
de San Francisco, dice, después de hacer algunas consideraciones sobre el color de su cutis, que no sabría precisar:

si era bella desde el punto de vista de la estética; pero había tal gracia en el precioso conjunto de sus facciones y tal encanto en la modesta actitud de su continente, que era imposible dejar de sentirse arrastrado hacia ella por una atracción fascinadora. Tal fue por lo menos la impresión que produjo en mí, y acaso no habría apartado los ojos de ella por todo el tiempo que me lo permitiese su permanencia en el templo, si no hubiese temido disgustarla con mi insistencia.

Hice un esfuerzo poderoso sobre mí mismo y afecté continuar en el examen de las bellezas que me rodeaban. Pero ya no había allí nada que pudiese fijar mi atención, y mis ojos se convertían involuntariamente a cada instante hacia la modesta joven vestida de negro.

$E Y$ y $C L$ cambian el verbo se convertían por "convergían". Converger, dice el Nuevo Diccionario de la Lengua Castellana (París/México: Bouret) en su edición de 1887, es "Dirigirse, encaminarse progresivamente dos rectas con una inflexión semiparalela a un mismo punto de reunión o contacto". Por su parte el Diccionario de uso del español de María Moliner, asienta que converger o convergir es "Unirse dos líneas, caminos, etc., en cierto punto". Y si pensamos que las miradas de los ojos del alférez "se convergían" en María, podría aceptarse como correcta la variante de $E Y$ y $C L$. Pero convertir, además del significado de "mudar, cambiar, trocar, transformar, metamorfosear, volver una cosa en otra" $(N D L C)$, acepción por lo que parece que no satisfizo a $E Y$ ni a $C L$, también significa 'volver o dirigir hacia cierta cosa', aunque esta acepción no figura claramente en el Diccionario de la Academia de la Lengua Española, según aclara María Moliner. El Diccionario de Autoridades dice que convertir: "Vale también volver, enderezar, dirigir". En latín converto, convertis, convertere, converti, conversum, aparte de 'cambiarse, mudarse o convertirse', también significa 'volverse o dirigirse hacia': convertere se ad iudicem ('volverse hacia el juez'), Quintiliano; omnium oculos ad se convertebat ('atraía hacia él las miradas de todos'), Cornelio Nepote; animos hominum ad me converteram ('había atraído hacia mí la atención de las gentes'), Cicerón. ${ }^{2}$ No era, pues, necesario cambiar

2 Todos estos ejemplos están tomados del Diccionario Latino-Español de Agustín Blánquez Fraile (Barcelona: Editorial Ramón Sopena, 1982). 
se convertían por "se convergían". Eligio Ancona escribía dentro de la tradición latina y castellana.

5. En el capítulo VII de la Primera Parte, cuando el alférez se dirige por segunda vez al convento de San Francisco con la finalidad de volver a ver a María, pero al mismo tiempo con el temor de no encontrarla, no puede más que expresar su alegría cuando la vislumbra en el mismo lugar en el que la había visto un día antes:

¡Oh felicidad suprema! ¡Ella estaba allí, más bella... más arrebatadora... más espiritual que nunca!

Quizá no había notado todavía mi presencia, porque mis ojos no se encontraron con los suyos. Pero súbitamente los levantó y cruzamos una mirada rápida, como las del día anterior. ¡Oh! Esta vez sí puedo jurar que no me equivoqué. Yo vi subir a sus mejillas un delicioso rubor... ese rubor divino que la naturaleza ha concedido a la mujer para ahorrarle la mortificación de confesar con los labios sus sentimientos.

Yo pude desde este instante forjarme la ilusión de que, cuando menos, no le era indiferente a mi hechicera desconocida, y halagado por esta idea, clavé en ella una mirada fija, firme, desapiadada, con la esperanza de que al fin levantaría los ojos de su libro de oraciones, para mirarme también.

Más adelante, en el capítulo VIII de la Primera Parte, cuando tiene lugar una de las primeras entrevistas de Ramiro con María en la ruinas de Santa Catarina y empieza a adivinar las aflicciones de su amada, escribe: "Y las lágrimas que había pugnado por contener en sus ojos, se escaparon entonces desapiadadamente, empañando por algunos instantes el brillo de sus pupilas".

El Diccionario de Autoridades dice: "Desapiadado, da. Adj. Cruel, inhumano. Es compuesto de la preposición Des, y la voz apiadado". Y agrega, como es usual, varios ejemplos en donde aparece la palabra. Desapiadado, desapiadadamente también los registra el Diccionario Castellano de las voces de ciencias y artes y sus correspondientes en las tres lenguas francesa, latina e italiana de Esteban Terreros y Pando (4 vols., Madrid: Imprenta de la Viuda de Ibarra, 1786-1793). EY y CL cambian desapiadada por "despiadada" y más adelante desapiadadamente por "despiadadamente" en atención de que la primera palabra les parece poco usual e incluso un arcaísmo. Julio Cejador y Frauca en su Lengua de Cervantes. Gramática y Diccionario de la lengua castellana en el Inge- 
nioso Hidalgo Don Quijote de la Mancha, t. II (Madrid: Establecimiento Tipográfico de Jaime Retés, 1906: 371), asienta que desapiadado era palabra que se puede documentar en el Quijote. Sabemos que Eligio Ancona había leído el Quijote; una prueba irrefutable es la presencia en algunos artículos de su revista satírica La Píldora, publicada en Mérida entre el 20 de junio y el 25 de agosto de 1866, del Dr. Pedro Recio de Tirteafuera, personaje del Quijote que alterna con Sancho en el episodio de la Ínsula Barataria. Además habría que recordar que era un gran conocedor de los dramaturgos del Siglo de Oro.

Ahora bien, si Ancona escribió desapiadado y desapiadadamente habría que dejar estas palabras tal cual se encuentran en la novela, en atención a su lectura de los clásicos españoles.

6. En el mismo capítulo VII de la Primera Parte, cuando Ramiro y María se encuentran por primera vez en la iglesia del Convento de San Francisco, María se hace acompañar por una criada llamada Marta, y Ramiro, para indicar el amor que le inspiraba, dice:

Yo tuve celos de este libro, de los sacerdotes que cantaban la misa, del altar, de los cuadros y de las estatuas de los santos... de todo en fin lo que me robaba una atención que en mi egoísmo, creía que a mí solo debía pertenecer.

También tuve celos de la vieja criada que la acompañaba y a quien algunas veces hacía oír el dulcísimo timbre de su voz, porque no podía menos que ser deliciosa la voz que salía de aquellos labios, rojos como el carmín.

$E Y$ y $C L$ cambian la palabra criada por "dueña”, quizá con la intención de diferenciar a este personaje de Juana, otra de sus sirvientas, una mujer indígena, que solamente hablaba maya, en quien ella había depositado toda su confianza hasta el grado de que de ella se hace acompañar cuando huye al lado de Ramiro. A Marta, María también la llama criada, a pesar de las labores que desempeñaba en su casa, según explica en el capítulo VIII de la Segunda Parte: "Marta es una antigua criada de mi casa, en quien mi padre deposita toda su confianza. Tiene un talento, o más bien una malicia especial para la intriga, y él la emplea frecuentemente en comisiones reservadas, de que sólo tengo noticias por las repetidas veces que sale a la calle, sin dar cuenta a nadie de sus acciones". 
Si el narrador y los principales personajes de la novela la llaman criada, e incluso la misma Marta le dice al alférez que ella es criada de María, no veo la razón de cambiarle este nombre por el de "dueña", aunque la acción de la novela transcurra en la Colonia, esto es, en los últimos ańos del siglo XviıI en Mérida.

7. En la segunda entrevista que tiene el alférez con la "bella desconocida", cuando ella todavía no le ha dicho su nombre, comete la imprudencia de llamarla María, y ella con sorpresa le pregunta: "—¿Quién os ha dicho que me llamo María?”. Y él contesta: “—¿Tan difícil os parece que se averigüe el nombre de la persona por quien uno se interesa?” Tal respuesta se explica debido a que su nombre se lo había dado Marta, y él hubiera dado lugar a un "perjuicio" (Primera Parte. Capítulo IX) delatando a la criada. EY, CL cambian perjuicio por "perjurio", y en efecto Marta antes de hacerle prometer que no la seguiría a ella, ni a María, y mucho menos revelar que ella iba a reunirlos en Santa Catarina, le había dicho: "-Yo confío, señor oficial, en que sois un hombre de bien y de conciencia, y que no quebrantaréis el juramento que voy a exigiros, siquiera para no exponer a un severo castigo a esta pobre mujer que se presta a serviros" (Primera Parte. Capítulo IX).

Y el narrador agrega: "Pronunció estas palabras, como poseída de cierto terror y con acento tan conmovido que parecía imposible dudar de su sinceridad".

Está, pues, claro que existe un juramento y que al no cumplirse se justificaría la palabra "perjurio", pero también es evidente que Marta exige el juramento por temor a un "severo castigo", lo que justifica plenamente la palabra perjuicio.

8. Al inicio del capítulo XI de la Primera Parte al referirse el narrador a su último encuentro con María, dice: "esta escena que debía quedar fotografiada en mi alma como el recuerdo más dulce de mi vida, había terminado de una manera inesperada... fatídica... misteriosa". Y más adelante, en este mismo capítulo: "Dondequiera que yo estuviese, yo no oía ni veía más que a la mujer que había perdido. El dulcísimo eco de su voz retumbaba siempre en mis oídos... las escenas de Santa Catarina parecían fotografiadas en la retina de mis ojos". CL cambia fotografiada por "grabada" y fotografiadas por "impresas", y parece no faltarle razón, pues si la acción de la novela transcurre entre 1796 y 1798, hacia aquella época no se había inventado la fotografía. Se trata ciertamente en este caso de un anacronismo léxico; pero los anacronis- 
mos en general suele haberlos con frecuencia en esta clase de novelas. Ya Justo Sierra O’Reilly decía a propósito de La hija del judió, en una nota al capítulo I, que en las novelas históricas se suele "incurrir en uno u otro ligero anacronismo; que es muy difícil evitar en las composiciones de este género".

9. Cuando el alférez describe el interior de la casa de Pedro de Balbastro, el intérprete maya y supuesto amigo de don Lucas de Gálvez, en el barrio de la Mejorada, dice: "El interior de la casa estaba en armonía con el exterior. Las paredes estaban cubiertas de polvo y telarańas. Cuatro sillas de madera desvencijadas, una mesa sobre la cual aparecían una baraja grasienta y una hamaca de henequén colgada en el fondo, constituían todo el mueblaje". CL cambia mueblaje por "moblaje", en razón de que esta última palabra es la común en la norma del español actual. Pero Justo Sierra O’Reilly también escribe mueblaje. Al describir la casa de don Alonso de la Cerda dice: "Inútil es hablar del estilo y gusto del mueblaje que se usaba entonces en las casas principales de Mérida" ( $\mathrm{La}$ hija del judio. Primera Parte. Cap. I). El Diccionario del español yucateco de Miguel Güemez Pineda no registra esta palabra (México: UADY/ Plaza y Valdés, 2011). Pero $E Y$ no la corrige, por lo que supongo que a mediados del siglo xx coexistían ambas variantes. Mueblaje es una palabra propia del habla de los yucatecos del siglo xix, y como cuenta con la autoridad de la lengua literaria, no debe cambiarse y debe dejarse tal cual la escribió Eligio Ancona.

10. Durante la huida de Ramiro y María hacia las costas orientales de Yucatán, mientras Ramiro se ha ausentado con el propósito de fletar una embarcación que los aleje de la península, Jorge de Serralta, el supuesto padre de María, la sorprende en la aldea de pescadores donde habían encontrado asilo, y violentamente la hace regresar a Mérida. Al volver Ramiro a la aldea, no obtiene mayores noticias de la ausencia de María, entre otras razones porque los pescadores no hablan más que maya:

María! ¡María! — dije repetidas veces con la esperanza de que el nombre de mi amada, les haría comprender que deseaba yo verla desde luego.

Ellos volvieron a hablarme en lengua maya; pero por los ademanes con que acompañaron su jerigonza, hube de adivinar que María se había ido de allí. 
Un presentimiento doloroso me oprimía el corazón y corrí desalentado a la choza inmediata... Tampoco estaba ahí María, ni Juana... ni nadie.

Salí al extenso solar que constituía la propiedad de mis huéspedes y llamé a gritos a mi amada... pero sólo el eco respondió a mi llamamiento.

En lugar de desalentado, es decir sin aliento, por "el excesivo trabajo, fatiga y cansancio" como dice el Diccionario de autoridades, EY y $C L$ cambian la palabra por "desatentado", que el mismo Diccionario de autoridades define como participio de "Desatentar", esto es, "Turbar el sentido, perder o hacer perder el tiento". Ramiro podría encontrarse turbado al adivinar su infortunio o proceder atropelladamente, sin juicio ni tino, al no tener noticias de María. Pero lo que el narrador dice es que Ramiro se encontraba sin aliento, porque acababa de recorrer varias leguas a caballo para regresar a la aldea en donde había dejado sin protección a María, y sobre todo presa de la angustia de que algo hubiera sucedido al buscarla y llamarla y no encontrar respuesta. Creo que debe respetarse desalentado y desechar "desatentado" como una equivocada sustitución.

11. Al regresar el alférez a Mérida, después de su frustrada huida en compañía de María, la señora Manresa le cuenta que por fin se ha descubierto al verdadero asesino de don Lucas de Gálvez (o el que ella cree que es el verdadero asesino). El alférez le pregunta su nombre y ella contesta que Pedro de Balbastro:

—Nunca lo hubiera creído... ¿ ¡Y denunció a los asesinos?

- Se denunció a sí mismo.

— ¡Ah! —exclamé viendo confirmadas mis antiguas sospechas—. Él sin duda tuvo también participio en el crimen.

$\longrightarrow_{i N o . . . !}$ fue el autor principal.

—imposible!

- Es verdad que se hace imposible creer que el hombre en quien don Lucas de Gálvez depositaba todas sus confianzas...

-No... no es eso... El autor principal debe ser otro. Balbastro es un pobre diablo y... en fin ¡debéis estar mal informada!

-Es verosímil, pero yo os repito lo que dice todo el mundo. 
CL cambia participio por "parte". Y, en efecto, la locución tener o tomar participio es considerada como un vulgarismo. Francisco J. Santamaría en su Diccionario de mejicanismos dice: "Barbarismo muy usado por las personas incultas, en vez de participación, parte, en frases como ésta: yo no he tomado participio o no tuve participio, en tal cosa”.

Rafael Delgado publicó su novela La Calandria por entregas en la Revista Nacional de Letras y Ciencias durante 1890 (México: tomo III), y un año después en libro con innumerables cambios, adiciones y supresiones y que puede considerarse como su edición definitiva (Orizaba: Pablo Franch). En la primera edición, al hacer la semblanza de don Eduardo Ortiz de Guerra, el padre de la protagonista, había escrito:

Había recorrido medio país durante aquella época y terminado gloriosamente su carrera en Querétaro, donde peleó bizarramente a las órdenes de Miramón. Allí cayó prisionero. Daba gusto oírle narrar los episodios del sitio, referir las diversas salidas en que tomó parte y ponderar el heroísmo de sus jefes y la grandeza del caballeroso príncipe que bańó con su noble sangre el Cerro de las Campanas.

Al hacer la segunda edición, la primera en libro, cambió dos locuciones: "referir las diversas salidas" por referir las diversas partidas y "tomó parte" por tomó participio. Hay que notar que no se trata del habla de ninguno de sus personajes, sino del discurso del narrador, y Delgado prefirió usar las expresiones más populares y coloquiales. Si así procedió uno de los novelistas más correctos y castizos de la novela mexicana del siglo XIX, no veo por qué corregir el estilo de Eligio Ancona, a pesar de la definición de Santamaría.

Por otra parte, $C L$ solamente corrige esta palabra en el capítulo IV de la Segunda Parte; no lo hizo en el capítulo XIV de la Primera Parte, ni en las siguientes ocasiones en que vuelve a aparecer la locución tener participio. Prueba irrefutable de que no le parecía un barbarismo o bien que la edición de las Memorias de un alférez la había hecho con mucho descuido, porque algunas veces corregía y otras no. Creo que debe respetarse la palabra participio.

12. Un día después de que el alférez es informado por la señora Manresa sobre la aprehensión de Pedro de Balbastro, se dirige a ver a don Anastasio de Lara, el alcalde, con la finalidad de obtener más detalles, pues él tenía la sospecha de que Balbastro solo era uno de los 
que habían participado en el crimen de don Lucas de Gálvez. Pero el alcalde se niega a darle más detalles, debido a que le preguntaba más de lo que podía decirle, ya que, según le explica, "las diligencias del sumario exigen reserva":

La manera galante con que se me daba esta lección —dice-, me impidió insistir en mis averiguaciones. Una vez más se me escapaba la oportunidad de descubrir a aquel personaje misterioso que después de haber hecho matar a Gálvez, había intentado igual crimen en mi persona. Volvía a quedar expuesto a su secreta venganza y no era fácil prever cuándo se presentaría otra ocasión, como la que acababa de defraudar mis esperanzas. $\mathrm{Ni}$ aun me quedaba el recurso de solicitar un permiso para hablar con Balbastro, puesto que en aquel instante se hallaba ya en camino para una ciudad lejana, de la cual acaso no saldría jamás.

Salí avergonzado de casa del Alcalde. Acaso era mayor mi abatimiento que mi vergüenza. No sabía a dónde dirigía mis pasos. Experimentaba la necesidad de la locomoción. Huía sin saber de quién ni de qué (Segunda Parte, IV).

$C L$ cambia vergüenza por "venganza", debido a que la segunda palabra de este último párrafo era "avergonzado" y, según él de esta manera se evitaba el efecto cacofónico. Ciertamente, se evitaba la repetición, pero se atribuía al protagonista una cualidad a su conducta y a sus intenciones de las que no da nunca ejemplo a lo largo de la novela. El alférez Ramiro de Salazar no es personaje cuyas acciones se expliquen por la venganza. Él ha venido a Yucatán, aparte de a "labrarse un porvenir", con la intención de descubrir al asesino de don Lucas de Gálvez y así probar la inocencia de su primo Antonio y, de paso, de otras víctimas que se encontraban encarceladas en San Juan de Ulúa. Pero nunca sus acciones obedecen al sentimiento de "venganza"; él lo que quiere es que se haga justicia debido a ese "instinto generoso que nos impulsa a socorrer a nuestros semejantes", pero llevado a tal grado que varios de los personajes hacen notar su espíritu quijotesco. Decir que la conducta del alférez obedece a la "venganza", vendría a ser lo mismo si nosotros calificáramos a don Quijote de un caballero vengativo por el hecho de defender y amparar a los débiles, a los menesterosos y a los inocentes. Debe dejarse vergüenza y borrar la palabra "venganza". 
13. En el capítulo VIII de la Segunda Parte, cuando María continúa sus "Memorias", escritas con la finalidad de explicar su conducta al alférez, dice:

"Cien veces he tomado la pluma para continuar este manuscrito, y otras tantas se me ha caído de las manos antes de trazar la primera letra. Las escenas que voy a referir ahora son de tal naturaleza, que pluguiera al cielo que hubiese muerto antes de presenciarlas. Y ved hasta qué extremo me llenará de dolor, de vergüenza y hasta remordimiento lo que debo deciros, que me atrevo a añadir: ojalá no os hubiera conocido nunca para no verme en la necesidad de sincerarme ante vos, porque para esto necesito presentaros en toda su desnudez una verdad espantosa que jamás debiera revelar una hija... ¡A Ah no olvidéis que os he conjurado a reducir a cenizas estas Memorias para destruir con ellas mi confusión... mi pena... y la grave falta que cometo contra los deberes que impone el amor filial...!"

$E Y$ y $C L$ cambian confusión y escriben "confesión", porque, en efecto, los capítulos VII, VIII, IX y X de la Segunda Parte son unas "Memorias" y por lo tanto una "confesión". A lo largo de estos cuatro capítulos María cuenta a grandes rasgos su vida, desde la infancia hasta el momento en que conoce y se enamora del alférez Ramiro de Salazar. Pero son tan íntimos, tristes y dolorosos estos recuerdos, estos sentimientos, estas "memorias", que a cada momento expresa sus dudas, sus inquietudes, sus incertidumbres. Y no era para menos, pues Jorge de Serralta, su supuesto padre, nunca tuvo para con ella la menor muestra de carińo, al grado de que no se dejaba ver por ella al cabo de meses, y cuando siendo ya una jovencita se le acercó fue para obligarla a que correspondiera a Pedro de Balbastro, a quien su padre había contratado para asesinar a don Lucas de Gálvez. La palabra confusión ya había aparecido en el capítulo VII cuando Jorge de Serralta la obliga a salir al balcón de su casa para saludar a Balbastro: "Incliné los ojos, llena de confusión". Pero como EY le había puesto título a los capítulos de esta novela, que la prínceps, la única autorizada por Ancona no tenía, y al capítulo VIII lo había titulado "Confesión", parecía muy lógico cambiar en el primer párrafo la palabra confusión por "confesión", cambio que ratificó $C L$.

Cito otras variantes, sin contar las supresiones y adiciones: culpables: responsables $E Y, C L$; su señoría : su señora $E Y$, su señor $C L$; fungir: 
actuar $E Y, C L$; crei : creía $C L$; diferencias : preferencias $C L$; se verificase : se hiciese $E Y, C L$; pasar: parar $C L$; ceguedad: ceguera $E Y$, $C L$; ser: hacer $C L$; observaba: miraba $E Y, C L$; colorearse : colorearme $C L$; de amor: de amar $E Y$, CL; pasó : posó $C L$; alguna luz: luz cierta $E Y$, $C L$; que a juzgar por las noticias : que, al decir $C L$; guarecida bajo esta sombra: guarecida a esa sombra $E Y, C L$; pudiera : pudiese $E Y, C L$; pasaba : posaba $E Y$, se posaba $C L$; creía : creí $E Y, C L$; sentimiento : sentido $E Y, C L$; cuestión : emoción $C L$; un grito doble : un grito $C L$; menor: menos $C L$; al través: a pesar $C L$; se encorvó : se incorporó $E Y$, $C L$; la impelí : la tomé $C L$; con: por $C L$; gonces: goznes $E Y, C L$; ¿Qué más da un hombre que otro?: ¿Qué más da que sea un hombre o que sea otro? $C L$; delación : relación $C L$; sustituia : dejaba $C L ; E Y, C L$; era necesario : era indispensable $E Y, C L$; solo : sola $E Y, C L$; de reunir: de acopiar $E Y, C L$; alguna de esas niñadas : alguna frase de esas niñadas $E Y, C L$; que daba acceso : que conducía $C L$; convenimos: convinimos $E Y, C L$; lo di al olvido : lo eché en olvido $C L$; no sería trascendida: no trascendiera $C L$; convenía : conviene $C L$; $i b a$ : voy $C L$; era : es $C L$; dependia : depende $C L$; era: es $C L$; diese : de $C L$; podría : podrá $C L$; debía : debe $C L$; debió : deberá $C L$; conocía : conoce $C L$; serian : serán $C L$; estaba : están $C L$; debian : deben $C L$; habrian pasado : habrán pasado $C L$; hablaban : hayan hablado $C L$; debería: deberá $C L$; nombre: hombre $E Y$; aprehendido: apresado $C L$; habia ofrecido : ofreciera $C L$; y aún me asaltó la idea: y aún tuve la idea $C L$; habia verificado : había realizado $C L$; desplegar: despegar $C L$; aprehendiera: aprehendiese $E Y, C L$; a revelarme : a delatarme $E Y, C L$; a dar: a presentar $C L$; en aquel tiempo: en aquella época $C L$; por la memoria : por el recuerdo $C L$; se verificara : se realizara $E Y$, $C L$; le dé ganas : queden ganas $C L$; sentía : sentí $E Y$, $C L$; cerrara : cerraba $C L$; quien : que $E Y$, $C L$; refluía : afluía $E Y, C L$; Fue : Fueron $E Y, C L$; trabajaba : destrozaba $E Y, C L$; inverosimil : verosímil $C L$; ¿Podría amar por ventura: ¿Podría amar acaso $E Y, C L$; podian : podía $C L$; ambas : ambos $C L$; con los que no alcancen sagrado: con los que no alcancen refugio sagrado $E Y$, con aquellos otros que no alcancen refugio sagrado $C L$; maldecido : maldito $C L$; criados y dependientes : criados dependientes $E Y$, CL; las espias : los espías $E Y$, CL; que tenía una apariencia : cuya apariencia $C L$; brutal: bruta $E Y, C L$; aventuras : locuras $C L$; principal: piso principal $E Y, C L$; vida : idea $C L$; experimentó : sintió $E Y, C L$; pobre : propia $E Y, C L$; vino : fue $E Y, C L$; verificará : celebrará $E Y, C L$; divulgarlo : $E Y$, divulgarlas $C L$; habia ahi: estaba allí $C L$; se vagaron: divagaron $E Y, C L$; de mi primer es- 
poso : de mi esposo $E Y, C L$; verificó : tuvo lugar $E Y, C L$; nuestros amores : nuestro amor $C L$; con desaparecerla : con hacerla desaparecer $C L$; faja : tira $C L$; foja: hoja $C L$; hoja : tira $C L$; tener: contar $E Y$, $C L$; en mi ceguedad: en mi precipitación $C L$; disparando : disparado $E Y$, disparar $C L$.

Este cotejo entre las tres ediciones hasta ahora publicadas de las $\mathrm{Me-}$ morias de un alférez, nos lleva a la conclusión de que la más contaminada es la que preparó Antonio Castro Leal en 1964 para su edición de La novela del México colonial. Su primer error fue tomar como texto base la edición de la Editorial Yucatanense "Club del Libro" y no haber acudido a la prínceps, la cual, aunque no confiable del todo, pues se publicó de manera póstuma, es la más próxima a la redacción de Eligio Ancona. El segundo, no haber sido congruente con sus criterios de corrección, pues algunas veces corrige algunas palabras o locuciones y en otras ocasiones las deja intactas cuando también eran susceptibles de corrección. Y, el tercero, haber modificado el texto siguiendo la norma del español culto o al menos la que él consideraba como tal.

De esta manera tenemos como resultado que a las 145 variantes (entre erratas, cambios, adiciones y supresiones) de la Editorial Yucatanense "Club del Libro", Castro Leal ratifica 129 y agrega alrededor de 300 , lo que viene a dar un total de 429 variantes, en relación con la primera edición.

Es necesario, pues, intentar la primera edición crítica de las Memorias de un alférez. Una edición que tome como texto base la publicada por José María Pino Suárez en 1904, que, aunque con todos sus defectos —no imputables a su autor, sino a sus editores— es la más próxima a la voluntad artística de Eligio Ancona; que registre las variantes de las tres ediciones hasta ahora conocidas; y de ser posible que venga acompañada con una serie de notas de carácter lingüístico, histórico, geográfico $y$, en general, cultural, que permita una cabal y acertada comprensión de su texto tanto como documento como obra artística del lenguaje.

\section{BibLIOHEMEROGRAFÍA DIRECTA}

Ancona, Eligio. "Independencia”, en La sombra de Morelos. Periódico de la Sociedad de la Juventud Democrática. Independencia, libertad, igualdad, ley, progreso, reforma, Mérida, año 1 (enero de 1962): 1-2. 
Ancona, Eligio. La Cruz y la Espada. Novela histórica. Mérida: Impresa por Leonardo Cervera, 1864; 2 vols., París: Librería de Rosa y Bouret, 1866; Mérida: Editorial Yucatanense "Club del Libro", 1950; Barcelona: Aurea Editores, 2006 [y la versión electrónica en la que se toma como texto base la edición de la Editorial Yucatanense de 1950, prólogo de Óscar A. García Solana].

Ancona, Eligio. El filibustero. Novela histórica. Mérida: Imprenta a cargo de Leonardo Cervera, 1864; 2 vols., París: Librería de Rosa y Bouret, 1866; 2 vols., Mérida: Editorial Yucatanense "Club del Libro", 1950; en La novela del México colonial, t. I. México: Aguilar, 1964: 629-800; "Prólogo" de Celia Rosado Avilés, Mérida: Gobierno del Estado de Yucatán/ ICY, 2010.

Ancona, Eligio. La pildora, que a guisa de periódico administran al público, dos veces por semana, los doctores Sangredo y Pedro Recio de Tirteafuera, Mérida (junio-agosto de 1866).

Ancona, Eligio. Los mártires del Anábuac. Novela histórica. México: Imprenta de José Batiza, 1870; 2 tomos, Mérida: Editorial Yucatanense "Club del Libro", 1951; 2 tomos, México: Editora Nacional, 1956; en La novela del México colonial, t. I. México: Aguilar, 1964: 411-624; México: Conaculta, Planeta DeAgostini, 2004.

Ancona, Eligio. El conde de Peñalva. Novela histórica. Mérida: Imprenta de Manuel Heredia Argüelles, 1879; 2 vols., Mérida: Impresora Popular, 1940.

Ancona, Eligio. Memorias de un alférez. Novela histórica. Introducción de José María Pino Suárez, 2 vols., Mérida: Imprenta de "El Peninsular", 1904; Introducción de José María Pino Suárez, 2 vols., Mérida: Editorial Yucatanense. "Club del Libro", 1949; en la Novela del México colonial, I, México: Aguilar, 1982: 805-1002.

\section{BIBLIOHEMEROGRAFÍA INDIRECTA}

Algaba Martínez, Leticia. "De la periferia al centro: Los mártires del Anáhuac de Eligio Ancona", en Rafael Olea Franco. Literatura Mexicana del otro fin de siglo. México: El Colegio de México, 2001: 239-249.

Algaba Martínez, Leticia. Del pasado al futuro. Cuatro novelas históricas mexicanas. México: Universidad Autónoma Metropolitana, 2012.

Castro Leal, Antonio. "Eligio Ancona", "Prólogo" a Los mártires del Anáhuac, "Prólogo" a El filibustero, "Prólogo" a Memorias de un alférez, en La novela del México colonial, t. I. México: Aguilar, 1964: 405, 409-410, 627-628, 803-804. 
Cuervo, Rufino José. Apuntaciones críticas sobre el lenguaje bogotano. París: A. \& R. Roger y F. Chernoviz, 1907: 183.

Latino. "Memorias de un Alférez. Novela histórica de Eligio Ancona", en El Peninsular, Mérida (25 de diciembre de 1904): 1.

Latino. "Memorias de un Alférez. Novela histórica de Eligio Ancona. II", en El Peninsular, Mérida (7 de enero de 1905): 1.

MelÉndez, Concha. La novela indianista en Hispanoamérica $(1832,1889)$. Río Piedras: Universidad de Puerto Rico, 1961: 79-84, 95-97, 103-106.

Menéndez, Carlos R. Noventa años de historia de Yucatán. 1821-1910. Mérida: Compañía Tipográfica Yucateca, 1937.

Pino S[uárez]., José M[aría]. "Introducción” a Las Memorias de un Alférez, t. I. Mérida: Imprenta de El Peninsular, 1904: III-VIII.

Pino S[uÁrez]., José M[aría]. "Introducción a la novela 'Memorias de un Alférez", en El Peninsular, Mérida (1 de diciembre de 1904): 1.

Santamaría, Francisco J. Diccionario de mejicanismos. Razonado, comprobado con citas de autoridades, comparado con el de americanismos y con los vocabularios provinciales de los más distinguidos diccionaristas hispanoamericanos. 6a edición. Méjico: Editorial Porrúa, 2000.

FECHA DE RECEPCIÓn: 28 de agosto 2013.

FECHA DE ACEPTACIÓN: 2 de diciembre 2013. 